\title{
Analisis Biaya Pengangkutan Tandan Buah Segar Kelapa Sawit di PT. Berau Karetindo Lestari, Kecamatan Segah, Kabupaten Berau, Provinsi Kalimantan Timur
}

\author{
Cost Analysis of Oil Palm Fresh Fruit Bunches Transportation in PT. Berau Karetindo \\ Lestari, Segah District, Berau Regency, East Kalimantan Province
}

\author{
Syahril $^{1^{*}}$, Humairo Aziza ${ }^{1}$, Wartomo $^{2}$ \\ ${ }^{1}$ Program Studi Pengelolaan Perkebunan, Politeknik Pertanian Negeri Samarinda, Indonesia \\ ${ }^{2}$ Program Studi Pengolahan Hasil Hutan, Politeknik Pertanian Negeri Samarinda, Indonesia
}

*Corresponding Author: syahrileazy@gmail.com

\begin{abstract}
Abstrak
Penelitian ini dilatarbelakangi oleh keberhasilan pengelolaan pengangkutan Tandan Buah Segar (TBS), maka wajib untuk dapat memenuhi 4 sasaran pengangkutan TBS, yaitu yang pertama menjaga FFA (Free Fatty Acid) produksi perhari sebesar 2-3\%. Kurang lancarnya transportasi menuju PKS berisiko menimbulkan buah restan. Efeknya bisa meningkatkan FFA sehingga kualitas CPO menurun. Kedua, menjaga kapasitas atau kelancaran pengelolaan Pabrik Kelapa Sawit (PKS). Waktu pengolahan TBS di PKS telah ditetapkan berdasarkan taksasi potong buah. Kurang lancarnya transportasi akan menyebabkan kapasitas pengolahan tidak terpenuhi dan menyebabkan waktu pengolahan bertambah. Ketiga, menjaga keamanan TBS di lapangan. TBS yang telah dipotong dan disimpan di tempat pengumpulan hasil (TPH) sangat rentan terhadap pencurian. Pengaturan transportasi harus memastikan bahwa buah yang dikirim ke PKS tepat waktu. Keempat, menekan biaya transportasi (rupiah per kilogram TBS) seminimal mungkin. Pengelolaan pengangkutan TBS harus mampu menghasilkan biaya yang kompetitif dan efisien. Oleh karena itu, penelitian ini bertujuan untuk mengetahui biaya pengangkutan kelapa sawit. Penelitian ini menggunakan metode kuantitatif, hasil penelitian ini dapat disimpulkan bahwa besarnya biaya yang dikeluarkan perusahaan untuk kegiatan pengangkutan selama setahun adalah sebesar Rp.715.122.800.
\end{abstract}

Kata Kunci: Analisa, Biaya Transportasi, Kelapa Sawit.

\begin{abstract}
This research is motivated by the success of the management of Fresh Fruit Bunches (FFB) transportation, it is mandatory to be able to meet 4 FFB transportation targets. First is to maintain FFA (Free Fatty Acid) production per day of 2-3\%. The lack of smooth transportation to the PKS has the risk of causing restan fruit. In effect, it can increase FFA so that the quality of CPO decreases. The second is to maintain the capacity or smooth management of the Palm Oil Mill (PKS). PKS processing hours have been set based on the taxation of fruit cut. The lack of smooth transportation will cause the processing capacity to not be fulfilled and cause the hours to increase. The third is to maintain the security of FFB in the field. FFB that has been cut and stored at the collection point (TPH) is very vulnerable to theft. Transportation arrangements must ensure that the fruit is delivered to the PKS on time. Fourth, to keep transportation costs (rupiah per kilogram of FFB) to a minimum. The management of FFB transportation must be able to produce competitive and efficient costs. Therefore, this study aims to determine the cost of transporting oil palm. This study uses quantitative methods, the results of this study can be concluded that the company's costs for transportation activities for a year is Rp.715,122,800.
\end{abstract}

Keywords : Analysis, Transportation Costs, Oil Palm

\section{PENDAHULUAN}

Dibalik kejayaan minyak sawit pasti ada kendala yang dihadapi oleh pemerintah Indonesia untuk menjadi produsen minyak sawit nomor satu. Persoalan klasik dan struktural yang masih membelit usaha perkebunan dan industri kelapa sawit di Indonesia dan belum teratasi sampai sekarang antara lain persoalan input produksi (seperti bibit yang baik, pupuk dan pestisida), rendahnya produktivitas, buruknya infrastruktur (mulai dari jalan, pelabuhan timbun hingga pelabuhan ekspor) serta lemahnya strategi (Samhadi, 2006).

Produktivitas dan mutu tandan buah segar (TBS) terus ditingkatkan guna memenuhi permintaan dunia akan CPO 
(Crude Palm Oil) yang masih tinggi. Peningkatan produktivitas bisa dengan cara memperluas areal perkebunan, menambah kapasitas produksi dan mempertahankan rendemen agar tetap tinggi atau meningkat. Ada berbagai faktor yang mempengaruhi rendemen dan mutu. Faktor-faktor tersebut dapat langsung dilihat dari sifat pohonnya dan pemanenan TBS tepat pada waktu pemasakannya, penanganan pasca panen dan proses pengangkutannya.

Pengangkutan TBS merupakan salah satu bagian dari perencanaan dan pengendalian produksi. Proses produksi akan berjalan dengan lancar jika pasokan bahan baku yakni TBS selalu ada dan tersedia, tetapi dengan menjaga agar tidak terjadi penumpukan TBS. Hal ini karena TBS harus segera diolah. TBS yang terlalu lama tersimpan akan menurunkan mutu bahan. Pengangkutan TBS dengan cepat setelah dipanen adalah salah satu cara untuk menjaga rendemen dan mutu agar tidak turun dikarenakan kenaikan asam lemak bebas (ALB). Pengangkutan TBS yang telah dipanen tidak boleh terlalu lama, maksimal 8 jam, bila lebih dari 8 jam maka peningkatan asam lemak bebas akan sangat tinggi yang akan menyebabkan mutu dari produk yang rendah dan rendemen yang kecil serta akan menyebabkan output menjadi kurang.

Keberhasilan pengelolaan transportasi TBS wajib bisa memenuhi 4 sasaran transportasi TBS, yaitu yang pertama menjaga FFA (Free Fatty Acid) produksi perhari $2-3 \%$. Ketidaklancaran transportasi ke pabrik kelapa sawit (PKS) berisiko menimbulkan buah restan. Efeknya, dapat meningkatkan FFA sehingga kualitas CPO menjadi turun. Kedua yaitu menjaga kapasitas atau kelancaran pengelolaan PKS. Waktu pemrosesan PKS telah diatur berdasarkan taksasi potong buah. Ketidak lancaran transportasi akan menyebabkan kapasitas pengolahan tidak terpenuhi dan menyebabkan waktu pengolahan bertambah. Ketiga yaitu menjaga keamanan TBS di lapangan. TBS yang telah dipotong dan disimpan di tempat pengumpulan hasil (TPH) sangat rawan terhadap pencurian. Pengaturan transportasi harus dapat menjamin buah yang dikirim ke PKS tepat waktu. Keempat yaitu menekan biaya transportasi (rupiah per kilogram TBS) seminimal mungkin. Pengelolaan transportasi TBS harus mampu menghasilkan biaya yang kompetitif dan efisien (Lubis dan Agus,2011).

Berdasarkan latar belakang penelitian yang telah diuraikan, masalah yang dirumuskan adalah berapa besar biaya dalam kegiatan pengangkutan kelapa sawit selama satu tahun.

Berdasarkan latar belakang dan rumusan masalah yang ada, maka penelitian ini dilakukan dengan tujuan untuk mengetahui besar biaya yang dikeluarkan dalam kegiatan pengangkutan kelapa sawit selama satu tahun.

Hasil yang diharapkan dalam penelitian ini yaitu dapat memberikan informasi kepada perusahaan mengenai proses perencanaan pembiayaan pengangkutan kelapa sawit.

\section{METODE PENELITIAN}

\section{A. Waktu dan Tempat Penelitian}

Penelitian ini dilaksanakan di PT. Berau Karetindo Lestari di Kecamatan Segah Kabupaten Berau Provinsi Kalimantan Timur dengan lamanya waktu penelitian adalah 1 bulan terhitung mulai 21 Oktober sampai 21 November 2020.

\section{B. Alat dan Bahan}

Alat dan bahan yang digunakan dalam penelitian ini adalah laptop, kalkulator, kamera handphone. serta literatur/pustaka.

\section{Metode Pengambilan Data}

Metode pengambilan data pada penelitian ini dilakukan dengan cara sebagai berikut :

1. Observasi

Memastikan kondisi lapangan dan juga alat angkut yang dapat menyebabkan perusahaan mengeluarkan biaya pengangkutan.

\section{Pengambilan Data}

Data primer yang diperoleh melalui wawancara kepada asisten kepala (ASKEP) yaitu data tentang harga alat angkut, pajak dan banyaknya penggunaan bahan bakar. Data perawatan diperoleh melalui wawancara kepada asisten workshop, sedangkan biaya upah dan premi karyawan diperoleh dari krani afdeling. 


\section{Studi pustaka}

Mencari buku-buku, literatur, jurnaljurnal, dan referensi yang berkaitan dengan penelitian yang sedang dilakukan.

\section{Prosedur Kerja}

Prosedur kerja dalam penelitian ini dilakukan dengan cara sebagai berikut:

1. Pengambilan data harga alat angkut dan lama penggunaan.

2. Pengambilan data biaya pajak alat angkut.

3. Pengambilan data biaya upah karyawan.

4. Pengambilan data biaya bahan bakar.

5. Pengambilan data biaya perawatan.

6. Memeriksa dan mengolah data yang telah diperoleh, kemudian dilakukan analisis.

\section{E. Analisis Data}

Analisis yang digunakan untuk mengolah data yang diperoleh dari kegiatan pengangkutan TBS dari TPH ke pabrik kelapa sawit (PKS) adalah dengan analisis kuantitatif dengan menghitung kebutuhan biaya dalam kegiatan pengangkutan TBS di lapangan. Hasil wawancara kepada narasumber dan analisis lapangan, berupa faktor-faktor yang mempengaruhi biaya pengangkutan, diuraikan secara deskriptif.

Kompenen biaya yang akan dianalisis adalah sebagai berikut :

\section{Biaya pengangkutan TBS selama setahun}

\section{a. Biaya Tetap}

1) Biaya penyusutan

Untuk mencari biaya penyusutan yaitu dengan cara sebagai berikut:

$$
B s=\frac{P-S}{n}
$$

Keterangan :

Bs = Biaya Penyusutan

$\mathrm{P} \quad=$ Harga Alat

$\mathrm{S} \quad=$ Nilai Penyusutan

$\mathrm{n} \quad=$ umur ekomis

Sumber : Jurnal Agromast Tahun 2018

2) Biaya pajak

Untuk menghitung biaya pajak yaitu dengan cara menjumlahkan biaya pajak STNK kedua jenis alat angkut dan pajak $\mathrm{KIR}$.
3) Biaya upah berdasarkan HK

Untuk menghitung biaya upah karyawan berdasarkan hari kerja (HK) selama 7 jam kerja yaitu:

\section{2 bulan x upah HK selama sebulan}

\section{b. Biaya Tidak Tetap}

1) Biaya bahan bakar

Untuk menghitung biaya bahan bakar yang dikeluarkan dalam kegiatan pengangkutan yaitu dengan cara:

Jumlah bahan bakar yang dibutuhkan per hari $x$ hari kerja selama setahun $x$ harga bahan bakar per liter

2) Biaya perawatan

Untuk menghitung biaya perawatan kedua jenis alat angkut yaitu dengan mencari biaya perawatan apa saja yang dikeluarkan pada saat kegiatan pengangkutan. Biaya perawatan ada beberapa komponen yang terdiri dari:

a) Oli

Untuk menghitung biaya oli yang dikeluarkan selama satu tahun dalam kegiatan pengangkutan yaitu dengan cara:

Kapasitas oli yang dibutuhkan $x 12$ bulan $x$ harga oli per liter.

b) Filter oli

Untuk menghitung biaya filter oli yang dikeluarkan dalam kegiatan pengangkutan yaitu dengan cara:

Jumlah filter oli yang dibutuhkan selama satu tahun $x$ harga filter per unit

c) Bering

Untuk menghitung biaya bering yang dikeluarkan dalam kegiatan pengangkutan yaitu dengan cara:

Jumlah bering yang dibutuhkan $x$ berapa kali pergantian selama setahun $x$ harga bering per unit

d) Ban

Untuk menghitung biaya ban yang dikeluarkan dalam kegiatan pengangkutan yaitu dengan cara:

Jumlah ban yang digunakan $x$ berapa kali pergantian dalam setahun $x$ harga ban per unit 
3) Biaya premi

Untuk menghitung biaya upah karyawan berdasarkan hari kerja (HK) upah premi yaitu:

2 bulan $x$ rata-rata upah premi selama sebulan

Semua komponen biaya tersebut diolah dengan program Microsoft Office Excel dan disajikan dalam bentuk tabel biaya untuk mengetahui jumlah dari setiap komponen biaya serta total biaya pengangkutan yang dikeluarkan.

\section{HASIL DAN PEMBAHASAN}

\section{Sejarah Perusahaan}

Pada bula Juni 2010, PT. Berau Karetindo Lestari memperoleh pengesahan proposal (Rencana Teknis Pembangunan Kebun dan Pabrik Pengolah Kelapa Sawit Kapasitas 30 Ton TBS/Jam. Proposal ini sekaligus merupakan pedoman teknis jangka panjang dalam pembangunan perkebunan kelapa sawit yang akan dilaksanakan oleh PT. Berau Karetindo Lestari. Sedangkan pedoman teknis jangka pendek dituangkan dalam bentuk Rencana Kerja Tahunan (RKT). PT. Berau Karetindo Lestari telah melaksanakan kegiatan pembangunan perkebunan mulai tahun RKT 2012/2013 secara berkelanjutan dengan tetap mempedomani proposal (Rencana Teknis Pembangunan Kebun) yang telah dibuat, dan selanjutnya dituangkan dalam Rencana Kerja Tahunan (RKT) 2016/2017.

Rencana Kerja Tahunan (RKT) 2016/2017 berisi rencana dan realisasi kegiatan pembangunan perkebunan s/d semester II tahun 2017 serta Rencana Kegiatan Tahunan 2016/2017 yang meliputi pembibitan (nursery), pembukaan dan persiapan lahan tanam (land preparation), jembatan dan saluran tanaman kelapa sawit, pembangunan perumahan dan perkantoran pengadaan alat-alat. Kedudukan dan tempat PT. Berau Karetindo Lestari berlokasi di Kampung Long Ayan, Kecamatan Segah, Kabupaten Berau, Provinsi Kalimantan Timur.

Batas - batas PT. Berau Karetindo Lestari sebagai berikut :

- Sebelah Utara : PT. Agrindo Sukses
Abadi

- Sebelah Selatan : PT. Natura Pasific Nusantara

- Sebelah Barat : Kampung Long Ayan

- Sebelah Timur : Kampung Punan Malinau

PT. Berau Karetindo Lestari membangun perkebunan kelapa sawit di wilayah Kecamatan Segah, Kabupaten Berau. Lokasi kebun dapat ditempuh dari kecamatan Segah dengan perjalanan darat selama 1 jam.

\section{Biaya Pengangkutan TBS Selama 1 \\ Tahun}

Dari hasil penelitian yang dilakukan di PT. Berau Karetindo Lestari mengenai besar biaya pengangkutan TBS dari TPH ke pabrik kelapa sawit (PKS) dapat dibagi menjadi dua komponen biaya yaitu :

a. Biaya Tetap

Biaya tetap terdiri dari biaya penyusutan, biaya pajak dan biaya upah karyawan. Adapun rinciannya sebagai berikut:

1) Biaya penyusutan

Pada kegiatan pengangkutan di PT. Berau Karetindo Lestari menggunakan dua jenis alat angkut yang berbeda. Alat angkut yang digunakan untuk mengangkut TBS dari TPH ke loading ramp yaitu menggunakan traktor yang harga perolehannya sebesar Rp 426.000 .000 dengan penggunaan alat selama 3 tahun sehingga biaya penyusutannya sebesar $\mathrm{Rp}$ 18.300.000. Adapun cara perhitungannya sebagai berikut :

$$
\begin{aligned}
\mathrm{Bs} & =\frac{\mathrm{P}-\mathrm{S}}{\mathrm{n}} \\
\mathrm{BS} & =\frac{426.000 .000-371.000 .000}{3} \\
& =18.300 .000
\end{aligned}
$$

Setelah TBS di angkut ke loading ramp kemudian di lanjutkan pengangkutan ke pabrik menggunakan dump truck dengan harga perolehan sebesar Rp 458.000.000 dengan penggunaan alat selama 2 tahun sehingga biaya penyusutannya sebesar $R p$ 62.000 .000 . Adapun cara perhitungannya sebagai berikut: 


$$
\begin{aligned}
\mathrm{Bs} & =\frac{\mathrm{P}-\mathrm{S}}{\mathrm{n}} \\
\mathrm{Bs} & =\frac{458.000 .000-334.000 .000}{2} \\
& =62.000 .000
\end{aligned}
$$

\section{2) Biaya Pajak}

Pajak setiap jenis alat angkut pasti berbeda-beda. Dikarenakan PT. Berau Karetindo Lestari memiliki dua jenis alat angkut yang berbeda untuk kegiatan pengangkutan TBS. sehingga pajak kendaraan untuk traktor sebesar Rp. 8.000.000 per tahun, sedangkan pajak kendaraan untuk dump truck sebesar Rp 4.000.000 per tahun. Selain dari pajak kendaraan yang digunakan, untuk kegiatan pengangkutan juga memiliki pajak KIR atau pajak uji kendaraan bahwa kendaraan tersebut layak digunakan secara teknis. Jadi pajak KIR untuk traktor dan dump truck masing-masing sebesar Rp 150.000 per 6 bulan. Sehingga seriap tahun biaya yang dikeluarkan sebesar Rp. 600.000 .

\section{3) Biaya Upah karyawan}

Upah atau gaji karyawan supir traktor, supir dump truck dan pemuat di PT. Berau Karetindo Lestari adalah sama yakni sebesar Rp.135.464/ hari. Sehingga upah karyawan selama sebulan dengan hari kerja selama 25 hari sebesar Rp.3.386.600. jadi total upah yang dikeluarkan untuk masingmasing karyawan selama setahun yaitu sebesar Rp.40.639.200. Jadi, biaya upah untuk karyawan dalam kegiatan pengangkutan selama setahun sebesar Rp.162.556.800.

\section{b. Biaya Tidak Tetap}

Biaya tidak tetap terdiri dari biaya bahan bakar, biaya perawatan dan biaya upah premi karyawan. Adapun cara perhitungannya sebagai berikut :

1) Biaya Bahan Bakar

Biaya bahan bakar yang di keluarkan perusahaan untuk traktor dan dump truck sama, sebanyak 40 liter per hari. Untuk traktor 40 liter tersebut digunakan selama sehari dengan pengangkutan sebanyak 7 kali selama sehari. Sedangkan untuk dump truck 40 liter tersebut digunakan selama sehari dengan 1 kali pengangkutan dikarenakan jarak perusahaan dengan pabrik kelapa sawit yang sangat jauh sehingga membutuhkan bahan bakar yang banyak. Bahan bakar yang digunakan traktor dan dump truck sama-sama menggunakan solar dengan harga per liter sebesar Rp.9.400.

\section{2) Biaya Perawatan}

Biaya perawatan yang dikeluarkan perusahaan untuk kegiatan pengangkutan terbagi menjadi dua jenis alat angkut yaitu :

a) Traktor dari:

Biaya perawatan untuk traktor terdiri

1. Oli

Oli yang digunakan traktor dengan kapasitas 5 liter. Traktor mengganti oli sekali selama sebulan dengan harga oli Rp.35.000/ liter. Jadi traktor selama setahun mengganti oli sebanyak 12 kali dengan total harga sebesar Rp.2.100.000

\section{Filter oli}

Filter oli yang digunakan traktor diganti setelah 3 kali pergantian oli dengan harga sebesar Rp.125.000/unit. Traktor mengganti filter sebanyak 4 kali dalam setahun sehingga total biaya selama setahun pergantian filter untuk traktor sebesar Rp.500.000.

\section{Bering}

Bering yang digunakan traktor sebanyak 8 unit jadi dalam satu ban terdapat dua bering kiri dan kanan, bering traktor diganti setelah 2 bulan pemakaian. Harga bering per unit sebesar Rp.250.000. total pergantian bering selama setahun sebanyak 6 kali dengan total bering yang di butuhkan sebanyak 48 unit bering dengan total harga sebesar Rp.12.000.000

4. Ban

Ban yang digunakan traktor diganti setelah pemakain selama setahun dikarenakan ban traktor ini memiliki ukuran yang besar dan tebal sehingga membuat ban tersebut lebih awet digunakan. Harga ban traktor per unit sebesar Rp.2.800.000. Jadi total biaya yang dikeluarkan untuk melakukan pergantian ban selama setahun sebesar Rp.11.200.000.

b) Dump Truck terdiri dari: 
1. Oli

Oli yang digunakan dump truck sebanyak 10 liter dengan pergantian setiap bulan. Harga oli per liter sebesar Rp.35.000 dengan kebutuhan selama setahun sebanyak 120 liter, sehingga total biaya yang dikeluarkan untuk mengganti oli sebesar Rp. 4.200.000

2. Filter oli

Filter oli yang digunakan dump truck diganti setelah 3 kali penggantian oli, harga per unit untuk filter oli sebesar Rp.150.000. Sehingga total biaya untuk mengganti filter oli selama setahun sebesar Rp.600.000.

3. Bering

Bering yang digunakan dump truck sebanyak 12 unit, jadi dalam satu ban terdapat dua bering kiri dan kanan, bering dump truck diganti setelah pemakaian selama 6 bulan. Harga bering per unit sebesar Rp.225.000. Jadi total bering yang dibutuhkan selama setahun sebanyak 24 unit dengan total harga sebesar Rp.5.400.000.

4. Ban

Ban yang digunakan dump truck diganti setelah penggunaan selama 6 bulan karena tekstur ban dump truk lebih tipis dari pada ban yang digunakan oleh traktor dan juga jarak tempuh yang sangat jauh yang menyebabkan ban dump truck lebih cepat diganti dari pada ban yang digunakan oleh traktor. Harga ban dump truck per unit sebesar Rp.1.625.000 sehingga total biaya untuk mengganti ban dump truck sebesar
Rp.19.500.000 dengan jumlah ban yang dibutuhkan sebanyak 12 unit.

3) Biaya Premi supir

Dalam kegiatan pengangkutan TBS ke pabrik kelapa sawit menggunakan dua jenis alat angkut yang berbeda sehingga premi yang dikeluarkan perusahaan juga berbedabeda untuk supir traktor dan dump truck. Untuk premi supir traktor dari rata-rata pengangkutan per hari memperoleh upah sebesar Rp.171.600 dari jumlah tonase yang dihasilkan selama sehari sebanyak $34.320 \mathrm{Kg}$ dengan harga premi yang di berikan perusahaan sebesar Rp. 5.000/ton sehingga premi supir traktor selama sebulan sebesar Rp. 4.290.000. Jadi total biaya premi yang dibayar perusahaan untuk operator traktor selama 300 hari kerja sebesar Rp. 51.480.000. Sedangkan untuk supir dump truck dari rata-rata pengangkutan per harinya sebanyak 6.068 $\mathrm{kg}$ dengan biaya premi Rp. 5.000/ton sehingga operator dump truck mendapatkan Rp.30.340 premi per hari sehingga premi untuk supir dump truck sebesar Rp.758.500. selama sebulan. Jadi total premi untuk supir dump truck selama 300 hari kerja sebesar Rp.9.102.000. Karena PT. BKL tidak memiliki pabrik sendiri sehingga pengangkutan untuk dump truck hanya dilakukan sehari sekali pengangkutan untuk satu dump truck sedangkan untuk traktor mencapai 7 kali pengangkutan dalam sehari sehingga membuat perbedaan upah antar keduanya sangat jauh.

Tabel 1. Total Biaya

\begin{tabular}{lllc}
\hline No & \multicolumn{1}{c}{ Komponen Biaya } & Rp/tahun & \% \\
\hline 1 & Biaya Tetap & & \\
& a. Biaya Penyusutan & Rp 80.300 .000 & 11,23 \\
& b. Biaya Pajak & Rp 12.600 .000 & 1,76 \\
& C. Biaya Upah Karyawan & Rp 162.556 .800 & 22,73 \\
& Total Biaya Tetap & Rp $\mathbf{2 5 5 . 4 5 6 . 8 0 0}$ & $\mathbf{3 5 , 7 2}$ \\
2 & Biaya Tidak Tetap & Rp 225.600 .000 & 31,55 \\
& a. Biaya Bahan Bakar & Rp 55.500 .000 & 7,76 \\
& b. Biaya Perawatan & Rp 178.566 .000 & 24,97 \\
& C. Biaya Premi & Rp $\mathbf{4 5 9 . 6 6 6 . 0 0 0}$ & $\mathbf{6 4 , 2 8}$ \\
& Total Biaya Tidak Tetap & Rp $\mathbf{7 1 5 . 1 2 2 . 8 0 0}$ & $\mathbf{1 0 0}$ \\
\hline
\end{tabular}

Sumber : Data Primer Diolah Tahun 2021 
4) Biaya Premi Pemuat

Untuk premi pemuat juga terbagi menjadi dua dikarenakan pemuat untuk traktor dan dump truck itu berbeda. Premi pemuat untuk traktor dari rata-rata hasil kerja per hari memperoleh Rp.292.120 sehingga premi yang didapatkan selama sebulan sebesar Rp.7.303.000, sedangkan pemuat dump truck rata-rata premi yang didapatkan per hari sebesar Rp.101.700 sehingga premi yang didapatkan selama sebulan sebesar Rp.2.542.500. Premi yang diperoleh pemuat traktor dan dump truck memiliki perbedaan dikarenakan kondisi jalan dan jumlah pengangkutan yang dilakukan antara traktor dan dump truck yang berbeda.

Berdasarkan Tabel 1 dapat dilihat bahwa dari semua komponen biaya yang ada dalam kegiatan pengangkutan, biaya bahan bakar merupakan biaya terbesar yang dikeluarkan perusahaan, diikuti biaya premi, biaya upah karyawan, biaya penyusutan, biaya perawatan dan biaya yang paling kecil yaitu biaya pajak kendaraan.

Biaya bahan bakar yang dikeluarkan di PT.BKL sebesar $31,55 \%$ dari semua total biaya. Karena PT. BKL merupakan perusahaan yang baru berdiri, sehingga jalanan yang dilalui untuk mengangkut TBS masih dalam tahap perbaikan yang menyebabkan sering terjadinya amblas. PT. $B K L$ juga tidak memiliki pabrik sendiri untuk mengelola hasil produksinya, sehingga menyebabkan TBS harus diangkut ke pabrik milik perusahaan lain yang jarak tempuhnya \pm 2 jam dari PT. BKL ke pabrik. Oleh sebab itu PT. BKL harus mengeluarkan biaya yang lebih besar untuk biaya bahan bakar.

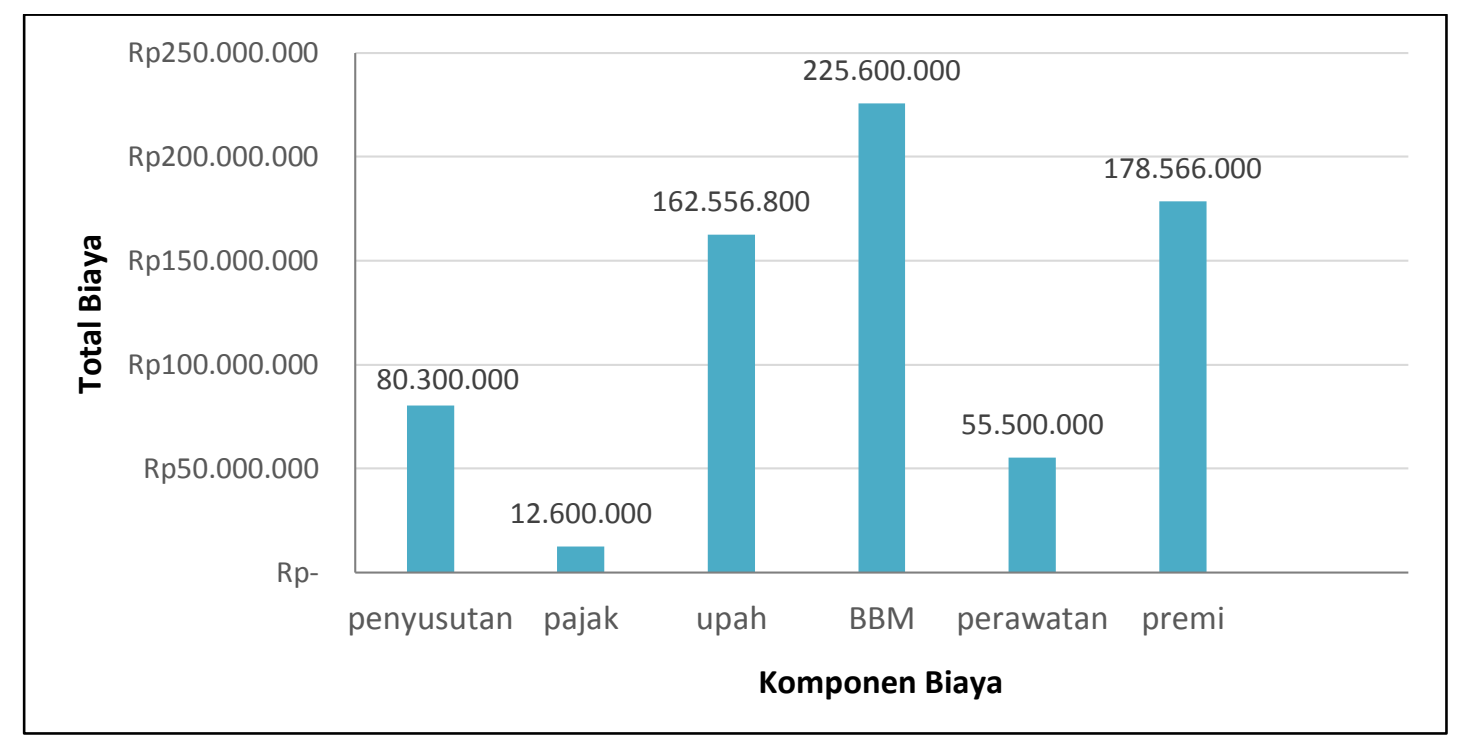

Gambar 1. Grafik Biaya

Dari grafik di atas, dapat dilihat bahwa dari semua komponen biaya dalam kegiatan pengangkutan TBS. biaya bahan bakar menduduki biaya terbesar dengan total biaya selama setahun yaitu Rp.225.600.000, sedangkan biaya yang paling sedikit yaitu biaya pajak sebesar Rp.12.600.000. Penelitian ini sejalan dengan penelitian yang dilakukan oleh Ningsih,T. (2018) yang menyatakan bahwa dalam kegiatan pengangkutan kelapa sawit, biaya terbesar yang dikeluarkan adalah biaya bahan bakar.

\section{KESIMPULAN}

Berdasarkan hasil analisis biaya pengangkutan kelapa sawit, biaya yang dikeluarkan dalam kegiatan pengangkutan kelapa sawit selama satu tahun di PT. Berau Karetindo Lestari yaitu sebesar Rp.715.122.800.

\section{DAFTAR PUSTAKA}

Anonim, 2012. Tahapan Pengembangan Perkebunan Kelapa Sawit.

Fitri Novitasari, A. A. 2016. Kajian Ekonomi Sistem Pengangkutan Tandan Buah Segar (TBS). Jurnal Masepi, Vol. 1, No.1.

Gilarso,T. 2003. Pengantar Ekonomi Mikro. Kanisius, Yogyakarta.

Hakim, M. 2013. Teknis Agronomi dan Manajemennya (Tinjauan Teori dan Praktis). Lembaga Pupuk Indonesia. Jakarta. 
Hudori,M. 2016. Perencanaan Kebutuhan Kendaraan Angkut Tandan Buah Segar (TBS) di Perkebunan Kelapa Sawit. Malikussaleh Industrial Enginering Journal, 5(1), 40-45.

Lubis, Widanarko, A. 2011. Buku Pintar Kelapa Sawit. Agromedia Pustaka, Jakarta.

Ningsih, T. 2018. Kajian Biaya Pengangkutan Tandan Buah Segar (TBS) Kelapa Sawit (Elaeis guineensis Jacq) di Areal Berbukit dan Areal Rendah/ Labil dengan Menggunakan Wheel Tractor di Divisi II Kebun Tanjung Keliling PT. Langkat Nusantara Kepong . Al Ulum Seri Sainstek, 1.

Pahan, lyung . 2008. Panduan Lengkap Kelapa Sawit. Penebar Swadaya. Jakarta.

Purwanto. 2016. Tips Sukses Usaha dan Berkebun Sawit. Cetakan pertama. Forest Publishing,Jawa Barat. Hal: 63 dan 9495.

Sahmadi, Sri Hartati, 2006. Ironi Sawit dan Ambisi Nomor Satu Dunia. Kompas Edisi Sabtu, 25 Februari 2006.

Siska Amalia Iradati, A. A. 2016. Kajian Transportasi Pengangkutan TBS Kelapa Sawit. Jurnal Masepi, Vol.1, NO.1.

Sumangun, H, Widodo, S. Soedjono, M. Hardiman dan Muljanto, D. 2005. Kemitraan Usaha Perkebunan. Fakultas Pertanian Universitas Gajah Mada. Yogyakarta. 